\title{
Correspondence: Demand avoidance is not necessarily defiance
}

The Lancet Child \& Adolescent Health, Volume 2, Issue 7, July 2018

Elizabeth O’Nions, Francesca Happé, Essi Viding, Judith Gould, Ilse Noens

Jonathan Green and colleagues ${ }^{1}$ have usefully outlined possible mechanisms that might represent vulnerability factors promoting habitual avoidance of routine demands in autism spectrum disorder and other developmental disabilities. However, we are concerned that conceptualising pathological (or extreme) demand avoidance as a set of comorbidities, including oppositional defiant disorder, could encourage the automatic use of reinforcement based approaches to alter the child's response to demands, since these strategies form the core of parenting interventions for disruptive behaviour disorders in general. Instead, we argue for much-needed research to establish what interventions are most effective for problematic demand avoidance in autism spectrum disorder.

A large body of research suggests that for disruptive children without developmental disabilities, avoidance is typically motivated by the reward of not having to engage with demands. Although reward-driven problem behaviour occurs in developmental disabilities in contexts in which parents are distracted, numerous reports suggest that avoidance of demands is often driven by an aversion to complying ${ }^{2,3}$.In such cases, it appears that demands have become conditioned stimuli signalling threat and are experienced as sufficiently aversive to reinforce attempts to terminate them via a repertoire including distraction, diversion, and severe problem behaviour (e.g., harm to self and others).

Once high anxiety has been triggered by demands, attempting to alter behaviour via contingent reinforcement would be ineffective because it would not address the function of the behaviour: to reduce anxiety ${ }^{3}$. Such approaches run the risk of escalating difficulties (see, for example, a case report by Agazzi and colleagues ${ }^{4}$ ). Over time, inappropriate management would probably promote rapid escalation of extreme behaviour in response to demands ${ }^{5}$, which might generalise to other triggers (e.g., things not being on the child's terms). This process might contribute to the emergence of controlling behaviours in children with autism spectrum disorder and extreme demand avoidance ${ }^{6}$.

We welcome Green and colleagues' proposal that behaviours described in extreme demand avoidance be systematically assessed and included within diagnostic formulations. We would also argue against the application of terms such as oppositional defiant disorder, on the basis that the term defiant suggests that the difficulties result from the child's willfulness. Implying that the child's behaviour is a purposeful act primes caregivers to respond reactively. In fact, some children with autism spectrum disorder and extreme demand avoidance might simply be using all strategies at their disposal to avoid stimuli that they experience as highly aversive. Establishing evidence based interventions to help such children is a key priority.

\section{Author affiliations}

Parenting and Special Education Research Unit, Faculty of Psychology and Educational Sciences (EO'N, IN), Leuven Autism Research (EO'N, IN), KU Leuven, Leuven, Belgium; Developmental Risk and Resilience Unit, Clinical, Educational, and Health Psychology Research Department, Division of Psychology and Language Sciences, University College London, London, UK (EO’N, EV); Medical Research Council Social, Genetic and Developmental Psychiatry Centre, Institute of Psychiatry, Psychology and Neuroscience, King's College London, London, UK (FH); and National Autistic Society Lorna Wing Centre for Autism, Bromley, Kent, UK (JG) 


\section{Competing interests}

EO'N has received a post-doctoral fellowship from the Belgian Marguerite-Marie Delacroix Support Fund focusing on recalcitrant problem behaviours and extreme demand avoidance in autism spectrum disorder. JG is the former lead consultant at the UK National Autistic Society Lorna Wing Centre for Autism. Although she retired from this role in 2015, she continues to provide training on the Diagnostic Interview for Social and Communication Disorders (DISCO) internationally on behalf of the National Autistic Society. IN works as a consultant and supervisor at PraxisP, the expertise centre of the Faculty of Psychology and Educational Sciences at KU Leuven in Belgium. She is also a consultant for the Centres for Consultation and Expertise in the Netherlands (challenging behaviour in autism spectrum disorders), and provides consultancy to other organisations within Flanders. She also provides training on the DISCO. All consultancy work and training is part of her academic role at KU Leuven. The other authors declare no other competing interests.

\section{Correspondence}

liz.onions@,kuleuven.be

\section{References}

1. Green J, Absoud M, Grahame V, et al. Pathological demand avoidance: symptoms but not a syndrome. Lancet Child Adolesc Health 2018; 2: 455-64.

2. Lucyshyn JM, Irvin LK, Blumberg ER, Laverty R, Horner RH, Sprague JR. Validating the construct of coercion in family routines: expanding the unit of analysis in behavioural assessment with families of children with developmental disabilities. Res Pract Pers Sev Disabil 2004; 29: 104-21.

3. Brewer AT, Strickland-Cohen K, Dotson W, Williams DC. Advance notice for transition-related problem behavior: practice guidelines. Behav Anal Pract 2014; 7: 117-25.

4. Agazzi H, Tan R, Tan SY. A case study of parent-child interaction therapy for the treatment of autism spectrum disorder. Clin Case Stud 2013; 12: 428-42.

5. Patterson GR, Maccoby EE. Mothers: the unacknowledged victims. Monogr Soc Res Child Dev 1980; 45: $1-64$.

6. O'Nions E, Viding E, Floyd C, et al. Dimensions of difficulty in children reported to have an autism spectrum diagnosis and features of extreme/'pathological' demand avoidance. Child Adolesc Ment Health 2017; published online Oct 12. http://dx.doi.org/10.1111/ camh.12242.

\section{Citation}

O’Nions, E., Happé, F., Viding, E., Gould, J., \& Noens, I. (2018). Demand avoidance is not necessarily defiance. The Lancet Child \& Adolescent Health, 2(7), e14. https://doi.org/10.1016/S2352-4642(18)30171-8

https://www.thelancet.com/journals/lanchi/issue/current

Copyright Lancet Child \& Adolescent Health, released with a Creative Commons Attribution NonCommercial No Derivatives License 